\title{
Cannabinoid CB2 receptor immunolabelling in the healthy brain-still a live possibility
}

\author{
John C. Ashton • Yiwen Zheng • Cynthia Darlington • \\ Jean-Ha Baek • Paul F. Smith
}

Received: 21 November 2013 / Accepted: 5 December 2013 /Published online: 18 December 2013

(C) Springer-Verlag Berlin Heidelberg 2013

In their comprehensive and rigorous study, Cécyre and colleagues (Cécyre et al. 2013) were able to demonstrate cannabinoid CB2 receptor-specific labelling for a Cayman Chemical polyclonal antibody in the mouse retina. This contrasts with our (Baek et al. 2013) result using the same antibody for the mouse brain. The authors suggest that this discrepancy may be a result of the greater number of possible cross-reacting proteins in the brain compared with the retina. We would like to take the opportunity to put forward an alternative hypothesis, one that is perhaps more optimistic with respect to the use of this antibody on brain tissue. First, we note that the same antibody appears to bind to a crossreacting protein in the retina when Western blot is employed (Cécyre et al. 2013). Therefore, there is at least one other protein in the retina with an epitope that can bind to the antibody if the epitope is sufficiently accessible. Therefore, it appears that there is a protein with such an epitope in the retina such that it is available for antibody binding under the conditions of Western blot but not immunochistochemistry in the Cécyre et al. (Cécyre et al. 2013) study. Hence, we propose that the tissue processing procedures employed in their experiments were sufficient to unmask the epitope for CB2, whilst leaving the epitope for a potentially cross-reacting protein inaccessible to the antibody. By contrast, it could be that the procedures that we (Baek et al. 2013) employed in our own study unmasked both epitopes. If this hypothesis is correct, then it leaves the question of CB2 immunolabelling in the brain open. Hence, it would be very interesting if the protocols of Cécyre et al. (Cécyre et al. 2013) were employed for mouse WT and CB2 KO brain tissue-as if CB2 is present in the healthy brain, then such a procedure might be able to detect it.

Conflict of interest The authors have no conflicts of interest to declare.

\section{References}

Baek JH, Darlington CL, Smith PF, Ashton JC (2013) Antibody testing for brain immunohistochemistry: brain immunolabeling for the cannabinoid CB (2) receptor. J Neurosci Methods 216:87-95

Cécyre B, Thomas S, Ptito M, Casanova C, Bouchard JF (2013) Evaluation of the specificity of antibodies raised against cannabinoid receptor type 2 in the mouse retina. Naunyn-Schmiedeberg's Arch Pharmacol
J. C. Ashton $(\bowtie) \cdot$ Y. Zheng $\cdot$ C. Darlington $\cdot$ J.-H. Baek $\cdot$

P. F. Smith

Department of Pharmacology and Toxicology, School of Medical

Sciences, University of Otago, P.O. Box 913, Dunedin, New Zealand

e-mail: john.ashton@otago.ac.nz 